GLOBAL JOURNAL OF COMMUNITY MEDICINE VOL. 2 NO. 1 \& 2 2009: 53 - 59

COPYRIGHT@ BACHUDO SCIENCE CO. LTD PRINTED IN NIGERIA. ISSN 1597 - 9857

\title{
BELIEFS AND PRACTICE CONCERNING PREGNANCY DELIVERY AND PUERPERIUM IN RURAL AKWA IBOM STATE
}

\author{
E. J. UDOMA, A. E. UDO, A. M. ABASIATTAI, E. A. BASSEY, A. IGWEBE \\ AND J. E. EKABUA
}

(Received 16 October, 2008; Revision Accepted 20 August, 2009)

\begin{abstract}
Focus group discussions involving 100 rural women in five communities of Akwa lbom State, Nigeria were carried out over a six-month period. The aim was to determine if the beliefs and practices of our rural dwellers are such that contribute to maternal morbidity. The discussions revealed that the participants had a shallow knowledge of the causes of complications in pregnancy. Complications were largely attributed to spirits and other harmless events. Reducing physically demanding activities in pregnancy was ascribed to laziness and sexual intercourse was largely to be avoided. There was no food taboos specific to pregnancy, but food restrictions were described. Antenatal and intrapartum care by spiritual and traditional midwives was considered superior to orthodox care. Practices by the midwives include turning a baby in an abnormal lie, massaging the vagina with oil in labour; conducting delivery without gloves, pulling on the cord, manually removing or squeezing out the placenta if delivery is not spontaneous. Management of complications involves divinations, use of herbs and other concoctions, anointing oil, prayers and fasting. Puerperal seclusion practiced to varying degrees and maybe beneficial. Most beliefs and practices of our rural women are potential contributors to maternal morbidity. A few are harmless or even beneficial. Public enlightenment and education of our rural dwellers while incorporating the harmless/beneficial practices into modern obstetric care services will help reduce maternal morbidity.
\end{abstract}

KEYWORDS: Pregnancy, Beliefs and Practices

\section{INTRODUCTION}

With a maternal mortality ratio of $1000 / 100,000$ live births; Nigeria has one of the largest burdens of maternal deaths in the world. (Oguniyi, Faleyimi et al 2003, UNDP 2001). The main medical causes of these deaths are haemorrhage, eclampsia, obstructed labour, sepsis and unsafe abortion (WHO 1999, Harrison 1997). It has been estimated that for every maternal death that occurs, 15 other women suffer chronic debilitating injuries (Moore 1991). Some of these morbidities (e.g. obstetric fistulae, palsy, infertility, gynaetresia and genital prolapse) have devastating social and psychological consequences for their victims, often for life.

Poor utilization of modern obstetric care services contributes remarkably to the high prevalence of morbidities in developing nations including Nigeira (Ogunniyi, Faleyimi et al 2000, ljadunola and Fatusi 2003). Studies show that majority of our women prefer to engage the services of traditional and spiritual midwives when pregnant (Udoma, John et al 2003, Etuk Etuk et al 2000). This is partly because the women easily identify with these midwives with whom they share common socio-cultural beliefs and practices (Udoma, John et al 2003).

E. J. Udoma, Department of Obstetrics \& Gynaecology, University of Calabar, Calabar, Cross River State, Nigeria

A. E. Udo, Department of Obstetrics \& Gynaecology, University of Calabar, Calabar, Cross River State, Nigeria

A. M. Abasiattai, Department of Obstetrics \& Gynaecology, University of Uyo, Uyo, Akwa Ibom State, Nigeria

E. A. Bassey, Department of Obstetrics \& Gynaecology, University of Uyo, Uyo, Akwa Ibom State, Nigeria

A. Igwebe, Dept. of Obstetrics \& Gynaecology, Nnamdi Azikiwe University, Nnewi, Anambra State, Nigeria

J. E. Ekabua, Department of Obstetrics \& Gynaecology, University of Calabar, Calabar, Cross River State, Nigeria 
Unfortunately some beliefs and practices such as female genital mutilation and the traditional abhorrence of abdominal delivery have been identified as harmful to maternal health (chukwudebelu 2003). Although anthropological studies have also been carried out in our environment, these have tended to focus on traditional believes pertaining to childbirth (Udoma, Asuquo, Ekott 1999). There is paucity of community-based research seeking to investigate the traditional beliefs and practices pertaining to pregnancy from the antenatal to the postpartum period that could contribute to maternal morbidity in rural Akwa Ibom State, Nigeria. This study aims to bridge this gap in knowledge in the hope that the outcome will enable the formulation of polices aimed at overcoming the existing socio-cultural barriers to achieving a reduction in maternal morbidity in our environment.

\section{MATERIALS AND METHOD}

This qualitative study was carried out between $1^{\text {st }}$ June, 2007 and $1^{\text {st }}$ December, 2007 in five communities Uruan, Abak, Eket, Oron and Ikot Abasi Local Communities of Akwa Ibom State with the aim of determining the following:

1. Beliefs about causes of diseases in pregnancy and practices to prevent and treat them.

2. Antenatal care practices.

3. Delivery practices and experiences during childbirth.

4. Postpartum practices including management of common complications.

This research group included medical doctors, nurses and a sociologist with experience in conducting focus group discussions (FGD). Their familiarity with the techniques made formal training unnecessary, although practice sessions were held. The topics that were covered in the FGD were devised by the researchers with advice from the sociologist. Before the questions to be asked were finalized, they were discussed with the researchers living in the study area to test the acceptability of the questions and to discern the likely form of the responses. The actual discussions in each community were facilitated by five female research assistants who live in the different communities. These women were given the questions in advance to translate into the commonly spoken rural dialect of the area of study. In order to obtain a comprehensive picture of experiences and opinions within the community, mothers of all ages, the traditional birth attendants (TBAs) and spiritual church midwives were included in the focus groups. It was felt that mothers would talk more freely of their experiences at childbirth if they were in a separate group from the birth attendants and similarly, that young mothers would feel less inhibited if separated from the older women. Thus five groups were devised and composed of:

(i) Mothers less than 25 years of age.

(ii) Mothers with five or more births but above 25 years.

(iii) Older mothers with influence in the community but above 60 years.

(iv) TBAs - trained and untrained.

(v) Spiritual church midwives.

Participants for the groups were chosen by researchers who were familiar with the community of study Purposive sampling method was used to broadly reflect each community in terms of their religious affiliations, educational level and socio-economic status. Filed-workers were particularly careful to include women from the poorest sections of the community. Each community had 20 participants in the focus group, each four from the group, and FGD session lasted a maximum of ninety minutes. Participants were offered refreshments during the sessions. Discussions were held in village halls and where there was none, the village heads' sitting rooms were used. Potential onlookers of both gender and older children were barred from the venue during the discussions. The facilitator introduced each topic or question for general discussion and then probed as was necessary. Discussions were not allowed to wander off into unrelated areas. It was ensured that all participants were given the opportunity to speak and that the discussions were not dominated by the most vocal women.

Written records were kept by one of the researchers who did not participate in the discussion. The entire discussion was recorded on a tape recorder and this was subsequently used to cross check the written transcript. Although the participants were informed that the discussion was recorded, they were not in anyway inhibited in their discussions. A total of 5 focus group one for each community of 20 participants were conducted. The topics that were discussed are as documented on Table 1. 


\section{RESULTS}

\section{i. BELIEFS ABOUT THE CAUSES OF COMPLICATIONS IN PREGNANCY}

The participants expressed overlapping ideas about disease causation in pregnancy, childbirth and the puerperium. These were attributed principally to the handiwork of spirits. A view held by all the participants was that witches and wizards (ifot) caused most illnesses in the communities. including complications in pregnancy. A spiritual birth attendant cited an example of her last client who had a quarrel with her mother's sister, a known witch and the witch had told her "she will see". The woman narrowly escaped death as she bled heavily before the onset of labour and delivered a dead baby. When the TBA was asked if she had ever heard of detachment of the placenta before delivery, her reply was that hospital people always try to explain everything. Water deities (ndem mmong, ebe ndap) were also cited as causing pregnancy complications, particularly miscarriages.

Violating the customs of the land were also said to cause complications in pregnancy and/or death of the woman involved. The offences mentioned by all the communities included failure of a man to perform the traditional rites of marriage prior to pregnancy, failure to offer a certain sacrifice during the marriage rites of a first daughter (nkpo adiaha owo) and adultery. To remedy the punishment for adultery, the woman has to confess to the husband so that the spirits protecting fidelity (ekpo nka owo) can be appeased. The participants were however reluctant to cite specific examples in this instance, but mentioned that most of the women died after a long labour. When asked if any of them was taken to hospital, the reply was that since the cause was known, that was not an option. When they were asked how it was known that the women were actually unfaithful since the accusations were denied, the response was that the help of diviners is usually sought when labour becomes difficult. The belief in violating traditional marriage rites as a cause of pregnancy complications was common to the older women and the TBAs. While some spiritual midwives agreed with this view, a few were of the opinion that it was an ancient tradition of the elders aimed at collecting more dowries from their in-laws.

Other causes of complications in pregnancy mentioned by the discussants were eating certain foods, not taking enemas frequently to wash the stomach, failure to massage the abdomen adequately following the last delivery to remove bad blood that accumulated. They also mentioned that if a pregnant woman bends down to eat, the baby will come with the legs; if she drinks water from the bottle, the baby will aspirate in the womb and may die; if she puts her hands on her head in labour, the labour will stop and if she quarrels with her husband, the baby could die in the womb and return to where he came from.

\section{ii. FOOD TABOOS AND RESTRICTIONS}

There were no food taboos specific to pregnancy in all the communities, but the participants cautioned on the need to restrict certain foods. It was a common belief that eating of snails in pregnancy is the cause of a baby dribbling saliva (Uduoetap) while eating eggs predisposes the baby to becoming a thief later in life. Also, eating sweet foods was associated with difficult labour by many of the discussants and eating too much oil was believed to be the cause of yellowness of the eyes in the mother and the baby (Utoenyin). The women also stated that a pregnant woman should avoid "hot foods and pepper to prevent "internal heat" (Ufiop Idip) and heart burns (Ayigha) as these may cause abortion and premature labour. However, hot foods and drinks are encouraged in early puerperium as they are believed to encourage lactation and drainage of lochia.

\section{iii. PHYSICAL ACTIVITY}

The discussions revealed that women are still expected to fetch water, gather, hew and split firewood during pregnancy and also to engage in farm work. These activities were said to be particularly necessary towards the end of pregnancy to encourage the cord binding the baby to the mother to detach otherwise labour will be prolonged. Many of the women were of the opinion that only a lazy woman reduces her activities because of pregnancy and one older mother asked, "who will feed her children"?

Most of the discussants considered sexual intercourse an exercise to be avoided particularly in the puerperium. Resumption of sex was only considered proper after three months of childbirth otherwise the sperm could mix with breast milk in the system to cause ill-health and poor growth of the infant. This was cited as one of the reasons why women are nursed in their mother's homes for a period after delivery. Some of the women, majority of whom where younger 
women were of the view that frequent intercourse was necessary in the early months of pregnancy to enable the baby form completely otherwise the baby may not be normal.

\section{iv. ANTENATAL CARE PRACTICES}

Most of the mothers reported that they were more comfortable relying on older women in the family to guide them in pregnancy as well as utilizing the services of TBAs and spiritual midwives than attending health facilities. Majority of the TBAs and spiritual birth attendants were of the opinion that early ante-natal care is unnecessary unless the woman has problems. They stated that they usually follow up women from the fifth month of pregnancy till delivery, observing no fixed routine. At the first visit they aim to confirm if the pregnancy is in the maternal abdomen or outside the womb. Some mothers were however of the opinion that if a pregnant woman is healthy; she does not need check-ups. While majority of the midwives also said they usually examine the abdomen routinely to check for the lie of the baby, some objected to the practice as they felt it could cause miscarriage.

All the midwives said that they give advice on nutrition and how to prevent problems in pregnancy. Some of the spiritual and trained birth attendants also said that they usually advice the women to go for tetanus immunization (editibe), but others feared that it could lead to an abnormal baby. The TBAS said they prescribe herbal enemas/drinks and other concoctions (which they were reluctant to name) to prevent and treat illnesses in pregnancy. The spiritual midwives on the other hand said that they rely on spiritual directions to prescribe for each woman though they usually organize fastings for the women as they believe that pregnancy weakens women spiritually, making them vulnerable to satanic attacks. Some of the mothers however admitted to taking "blood medicine" which they buy from patent medicine dealers who cycle through the villages.

\section{DELIVERY PRACTICES AND EXPERIENCES DURING CHILDBIRTH \\ i. PLACE OF DELIVERY}

Majority of the mothers were of the opinion that the church is the best place to deliver as there is spiritual protection against satanic attacks hence safe delivery is guaranteed. A child delivered in the church would also receive divine blessings and is therefore more likely to survive into adulthood and be more successful than a child born outside the church. The mothers also said that TBAs are good birth attendants and they had the advantage over spiritual midwives of going to the women's houses to deliver them. On1y a few of the women thought it necessary to go to hospital for delivery even in the face of complications. According to one young mother whose last delivery was in hospital, "the hospitals are too far, the staff shout at you, they order you to lie down when you are in pains, they want money before they treat you, your mother cannot enter, they will not discharge you on time and will not let anybody help you with the baby". Another stated "when you go there, they will cut you. They like to cut". The birth attendants were asked if they refer ill women to hospital. In response, there was usually a pervading sense of their superiority over western medicine especially among the trained TBAs. The individual TBAs and spiritual midwives were always quick to respond that they never have reasons to refer cases to anyone. There was a general believe that health workers cannot solve problems, the TBAs and spiritual midwives cannot solve. If a woman died, it meant that the woman had already been killed spiritually and was just a walking corpse before even the onset of the complication.

\section{ii. CONDUCT OF LABOUR}

The TBAs and spiritual midwives of conducting normal and abnormal labour reflected the same pattern as they all said they massage the birth passage (usung eyen) with oil in order to accelerate labour and prevent tears. Women were usually delivered in the squatting position. The midwives also said that they turn the baby if the bay is not lying well. When asked if they use gloves during delivery, majority said they used their bare hands and had no reason to do otherwise.

\section{iii. DELIVERY OF THE PLACENTA}

Most of the attendants said they cut the umbilical cord after the delivery of the placenta including the trained TBAs who admitted that they had been trained to do so before placental delivery. Some of the attendants also said that they usually pull on the cord if the delivery of the placenta is delayed, some said they insert a hand into the vagina to remove the placenta, others said they massage the abdomen, while yet others squeeze he womb to expel the placenta. 


\section{BELIEFS AND PRACTICES PERTAINING TO THE PEURPERIUM AND SOME POSTPARTUM COMPLICATIONS}

i. Immediate Post Partum Haemorrhage

Post-partum haemorrhage referred to as

"Uwo iyip" was discussed with the groups. All the participants had an appreciation of the danger of the condition. In the words of one participant "sometimes the blood flows so much that it can fill two buckets". Some of the respondents however believed that passing of excess blood may be advantageous as the "bad blood of pregnancy" is washed off. Although the midwives knew that retained placenta could cause haemorrhage, they had no knowledge of the other risk factors. Use of herbs to arrest bleeding was the remedy to treat post-partum haemorrhage by TBA's, while the spiritual church midwives said they rely on herbs and prayers. Some said their churches had a standing prayer team to support them.

\section{ii. ECLAMPSIA AND TETANUS}

The participants were able to recognize spasms caused by tetanus (Odon) but these were attributed to spiritual attacks. One of the participants said she lost her baby due to this condition because her relation, a known witch touched her baby immediately after delivery. She sounded a strong warning against allowing visitors to carry newborn babies. The women were not able to differentiate between convulsions due to eclampsia and seizures due to epilepsy however. Although a local name (ndukpi) was cited for epilepsy, they cited no traditional name for convulsions in pregnancy. They were however of the general opinion that convulsions are due to possession by spirits. The relationship between oedema and the development of convulsions in pregnancy was unrecognized.

\section{iii. POST PARTUM SECLUSION}

Many of the participants exhibited anxiety during the discussion on post-partum seclusion. The women explained that this traditional practice is common with first births and is a modification of an older tradition that was performed on pubertal girls to prepare them for marriage (mbopo). It entails nursing the puerperal woman in a special fattening room, employing different tactics to ensure she is fattened and observing certain customary rituals. When the fattening period is over, she is then taken to the market square for her outing ceremony amidst pomp and pageantry. Her level of obesity is an indicator of her good health and her proud parents are congratulated and showered with gifts by their inlaws vis-a-vis her size. It was gathered that even this tradition is fast loosing grounds and the practices have been watered down, but mothers still take home their daughters to nurse (ukuk uman) to enable the new mother recover from the effects of pregnancy and childbirth and to educate and guide her on child care.

\section{DISCUSSION}

The study has revealed the existence of tenacious beliefs in the supernatural causation of diseases in pregnancy among the vast majority of our rural dwellers. It has also revealed why our women believe in the effectiveness of TBAs and spiritual church midwives over orthodox health care workers. The women share common customs and traditions with the birth attendants thereby sharing similar beliefs and practices concerning pregnancy and childbirth.

The study also revealed that there are no food taboos specific to pregnancy but intake of certain foods is expected to be restricted. These restrictions may not be of nutritional importance however as they either involve foods that are not usually affordable by such poor families (e.g. eggs) or the advice concerning some foods e.g. palm oil and sweet foods is usually to restrict and not to cut out the foods entirely. On the other hand, women are not expected to reduce their level of participation in farm work and other physically-demanding domestic chores when pregnant. This is probably bec9use a reduction in activity could affect the family negatively since women in rural African societies bear a lot of the economic and domestic responsibilities for the upkeep of their children. A tendency to rest, even in pregnancy, is therefore met with ridicule. The heavy work load coupled with the demands of pregnancy leave many of the women overworked, tired and malnourished and thus more vulnerable to illnesses and pregnancy complications (Chukwudebelu, 2003).

It was further revealed that the concept of prenatal care for a normal pregnancy is not alien to rural women although the practices differ greatly from orthodox antenatal care practices and some are potentially harmful. It was clear from the discussions that the women believed in the superiority of prevention over cure as obtains with orthodox care. That our rural women are slow to accept modern antenatal care services 
partly reflects a lack of health education and partly reflects the highly westernized nature of obstrictric care services, a model that is stange to the belief system of rural women. This westernized nature of obstetric care services explains in part why the magnitude of improvement in maternal helath from training TBAs is quite small as have also been suggested by other studies (Greenwood, Bradley et al 1987, Jordan 1998, John, Udoma et al 2002.)

Many of the delivery practices that were described are potentially detrimental for example using bared hands to conduct deliveries and in all likelihood contribute to maternal morbidity. A few of them were potentially harmless. Since such harmless practices are of psychological benefit to the women, they should be encouraged in health facilities to gain the acceptance of our rural dwellers. Such practices include allowing ambulation in labour when there is no risk to mother and fetus, allowing mothers and husbands entry to offer psychological support to a parturient and allowing women to assume a squatting position at delivery if they so wish. The delivery suits squatting position at delivery if they so wish. The delivery suits should be adapted to accommodate these practices where necessary.

The practice of seclusion after childbirth is still an important custom amongst our rural dwellers although this is now often a shadow of the hitherto practice where the women were forcefully fed to ensure they achieved a high level of obesity which was considered healthy and attractive (Udo, 1983). The modern day practice may be beneficial to women who do not end up obese as the central aim appears to be helping the puerperal woman recuperate from the effects of pregnancy and childbirth. It may prevent postpartum anaemia and ensure a healthy puerperal period since the women are usually given the choice parts of food for the period.

In conclusion, many of the socio-cultural beliefs and practices existing in our rural communities may predispose to tenet to encourage maternal morbidity among our women and should be discouraged. Public enlightenment programs and education for our rural dwellers is important in this regard. Also, incorporating the harmless and beneficial practices into modern obstetric care services will ensure gradual confidence in orthodox obstetric care and a gradual erosion of negative beliefs about hospital care. It is therefore important to incorporate topics which deal with the beliefs and practices of rural women into the curriculum for training of health care workers. These measures will go a long way in reducing maternal morbidity in our environment.

\section{TABLE 1: TOPICS DISCUSSED DURING THE SESSIONS}

1. Beliefs concerning complications in pregnancy, social activities and antenatal care practices.

(a) Beliefs about causes of dieses in pregnancy.

(b) Food restrictions in pregnancy.

(c) Physical activities in pregnancy.

(d) Antenatal care practices.

2. Delivery practices and experiences during childbirth

(a) Place of delivery and the health attendants.

(b) Conduct of normal labour and delivery of the baby.

(c) Delivery of the placenta.

3. Beliefs and practices pertaining to the puerperium and some post-partum complications.

(a) Immediate post partum haemorrhage.

(b) Eclapsia and Tetanus.

(c) Post-partum seclusion. 
TABLE2: SHOWING PARTICIPANTS' BELIEFS ABOUT CAUSES OF COMPLICATIONS IN PREGNANCY

Witches and wizards

Common Beliefs about causes of complications in Pregnancy

Marine spirits and deities

Violating the customs of the land e.g. failure to perform traditional marriage rites.

Adultery

Eating certain foods.

Not taking enema during pregnancy

\section{REFERENCES}

Chukwudebelu, W. O., 2003. Preventing maternal mortality in developing countries. In: Cotemporary obstetrics and Gynaecology for Developing Countries. Okonofua $\mathrm{F}$ and Odunsi K (Eds) .Ibadan: Intec Printers Ltd, pp. 644-57.

Etuk, S. J., Etuk, I. S., Ekott, M. I. and Udoma, E. J., 2000. Perinatal outcome in pregnancies booked for antenatal care but delivered outside health facilities in Calabar, Nigeria. Acta Tropica 75:29-33.

Greenwood, A. M., Bradley, A. K., Byass, P., Greenwood, B. M., Snow, R. W., Bennels, H., Atib-N Jie, A. B., 1987. Evaluation of a primary health care programme in the Gambia. The impact of trained traditional birth attendants on the outcome of pregnancy. Journal of tropical medicine and hygiene 93:58-66.

Harrisdn, K. A., 1997. Maternal mortality in Nigeria. The real issues. Afri. J Reprod. Health 1 (1): 7-13.

ljadunola, K. T. and Fatusi, A. O., 2003. Utilization, quality and performances of available maternity care services. Technical Report on Essential Obstetric care activities in Nigeria, pp. 27 - 42.

John, M. E., Udoma, E. J., Udoh, M. O., Ndebbio, T. J. and Idiong, M. S., 2002 Knowledge and practice of traditional birth attendants concerning risk factors in pregnancy, labour and peurperium. African journal of nursing and midwifery 4(1) 41 -49.

Jordan, B., 1998, Cosmopolitical obstetrics: some insights from the training of traditional midwives. Social science and medicine 28, 9:925 - 944.

Moore, R., 1991. Chronic maternal morbidity in developing countries: data synthesis and policy suggestions. Presentation at the 119th Annual meeting of the American Public Health Association, Atlanta, Georgia, No.1 ?91, 9, (10) .

Ogunniyi, S. D., Faleyimi, B. L., Makinde, O. N., Adejugbe, E. A., Ogunnyi, F. A. and Owolabi, A. T., 2003. Delivery care services utilization in an urban Nigerian population. Nigeria J. Med 2000; 9: 81 - 85

Udo, E. A., 1983, Ibibio social organization: Marriage and Kin. In: Who are the Ibibio? Onitsha: Africana-Fep Publishers Ltd, pp.162-193. '

Udoma, E. J., Asuquo, E. E. J. and Ekott, M. I., 1999. Maternal mortality from obstructed labour: The role of spiritual churches. Int $\mathrm{J}$. Gynecol Obstet. 67 103-105.

Udoma, E. J., John, M. E., Udosen, G. F. and Udo, A. E., 2003. Obstetric practices in spiritual churches in South-Eastern Nigeria. Mary Slessor J. med. 3:51 - 56.

UNDP, Nigerian Human Development report., 2000/2001. Millennium edition, United Nations Development Programme, Lagos, Nigeria, 2001.

World Health Organisation. Reduction of Maternal Mortality. A joint WHO/UNFPA/UNICEF/World Bank Statement, World Health Organisation, Geneva, 1999; 4-19. 